\title{
Uranium Carbide Fibers with Nano-Grains as Starting Materials for ISOL Targets
}

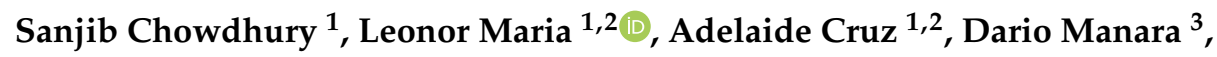 \\ Olivier Dieste-Blanco ${ }^{3}$ (1) , Thierry Stora ${ }^{4}$ and António Pereira Gonçalves $1, *$ (D) \\ $1 \quad \mathrm{C}^{2} \mathrm{TN}$, Instituto Superior Técnico, Universidade de Lisboa, Campus Tecnológico e Nuclear, \\ Estrada Nacional 10, 2695-066 Bobadela LRS, Portugal; sanjibbua@gmail.com (S.C.); \\ leonorm@ctn.tecnico.ulisboa.pt (L.M.); adelaide@ctn.tecnico.ulisboa.pt (A.C.) \\ 2 CQE, Instituto Superior Técnico, Universidade de Lisboa, Campus Tecnológico e Nuclear, \\ Estrada Nacional 10, 2695-066 Bobadela LRS, Portugal \\ 3 Joint Research Centre, European Commission, P.O. Box 2340, D-76125 Karlsruhe, Germany; \\ Dario.MANARA@ec.europa.eu (D.M.); Oliver.dieste@gmail.com (O.D.-B.) \\ 4 CERN-European Organization for Nuclear Research, 23 Genève, CH-1211 Genève, Switzerland; \\ thierry.stora@cern.ch \\ * Correspondence: apg@ctn.tecnico.ulisboa.pt
}

Received: 17 November 2020; Accepted: 6 December 2020; Published: 9 December 2020

\begin{abstract}
This paper presents an experimental study about the preparation, by electrospinning, of uranium carbide fibers with nanometric grain size. Viscous solutions of cellulose acetate and uranyl salts (acetate, acetylacetonate, and formate) on acetic acid and 2,4-pentanedione, adjusted to three different polymer concentrations, 10, 12.5, and 15 weight \%, were used for electrospinning. Good quality precursor fibers were obtained from solutions with a $15 \%$ cellulose acetate concentration, the best ones being produced from the uranyl acetate solution. As-spun precursor fibers were then decomposed by slow heating until $823 \mathrm{~K}$ under argon, resulting in a mixture of nano-grained $\mathrm{UO}_{2}$ and $\mathrm{C}$ fibers. A last carboreduction was then carried out under vacuum at $2073 \mathrm{~K}$ for $2 \mathrm{~h}$. The final material displayed $\mathrm{UC}_{2-\mathrm{y}}$ as the major phase, with grain sizes in the $4 \mathrm{~nm}-10 \mathrm{~nm}$ range. $\mathrm{UO}_{2+\mathrm{x}}$ was still present in moderate concentrations ( 30 vol.\%). This is due to uncomplete carboreduction that can be explained by the fiber morphology, limiting the effective contact between $\mathrm{C}$ and $\mathrm{UO}_{2}$ grains.
\end{abstract}

Keywords: nuclear targets; uranium carbides; nano-scale; electrospinning; fibers

\section{Introduction}

The Isotope Separation On-Line (ISOL) method is a technique used to produce radioactive-ion beams (RIBs) by irradiating a target with a high-intensity/high-energy particle beam. The particles of the beam (e.g., protons, electrons, and neutrons) interact with the nuclei of ISOL target constituents, producing radioisotopes through nuclear reactions, namely by fission, fragmentation, and spallation [1]. The products of the nuclear reactions first diffuse from the interior to the surface of the target and then evaporate/sublimate. ISOL targets shall operate at high temperatures in order to minimize the diffusion and releasing times of the radioisotopes. Next, the isotopes effuse to a mass separator, where they are ionized and separated based on their mass-to-charge ratio. They are finally transported to the application point. The RIB intensity, $\mathrm{I}_{\mathrm{RIB}}$, depends on the particular nuclear production cross-section of the desired isotope $i, \sigma_{i}\left(E^{*}\right)$, by the interaction of a particle of specific energy $\left(E^{*}\right)$ with the target nucleus, the number of target nuclei, $\mathrm{N}_{\text {target}}$, the driver beam intensity, $\mathrm{I}^{*}$, and the overall efficiency $\varepsilon$ (depending on the diffusion, releasing, effusion, ionization, separation and transport efficiencies).

$$
\mathrm{I}_{\mathrm{RIB}}=\sigma_{\mathrm{i}}\left(\mathrm{E}^{*}\right) \times \mathrm{N}_{\text {target }} \times \mathrm{I}^{*} \times \varepsilon
$$


ISOL targets can be in the form of pressed pellets, metallic foils, liquid metals, or fibers [2], with most of the target materials being refractory metals or ceramics, as oxides or carbides [3]. This method allows the production of a wide variety of radioisotopes through nuclear reactions [4]. The isotopes to be produced and the availability of the high-intensity/high-energy beam determine the choice of the nuclear targets. However, bulk, micrometric, $\mathrm{UC}_{\mathrm{x}}$-based targets are the current reference at most of the ISOL facilities [5]. ISOLDE (Isotope Separator On Line Device), at CERN, is an ISOL facility where uranium carbide targets interact with a $1.4-\mathrm{GeV}$ pulsed proton beam to produce radioactive nuclei for a number of different applications including: Atomic physics, nuclear physics, solid state physics, materials science, astrophysics, and medicine [6].

Uranium dicarbide, $\mathrm{UC}_{2-\mathrm{y}}$, is the best candidate target material due to the high fission yields in nuclear reactions, excellent stability at elevated temperatures, and large thermal conductivity [7]. It provides large yields for neutron-deficient isotopes of heavy elements, such as Ac, Ra, Fr, At, and Rn, as well as for neutron-rich radioisotopes with $70<\mathrm{A}<160$, where " $\mathrm{A}$ " represents the mass number [8]. For a long time, uranium dicarbides have been prepared by different techniques, with each of them having advantages and disadvantages.

For example, uranium carbide target disks with $14 \mathrm{~mm}$ in diameter and $1 \mathrm{~mm}$ of thickness were prepared from the metal oxide mixed either with an excess of graphite (U:C molar ratio of 1:4) or diphathalocyanine (U:C molar ratio of 1:13) [9]. The study of their behavior under pulsed beams showed that the release of $\mathrm{Li}$ and $\mathrm{Na}$ were fast with little decay losses. The production yield of ${ }^{225} \mathrm{Th}$ is about five times greater from this target $(16.4 \mathrm{mb})$, when compared to identical thorium carbide

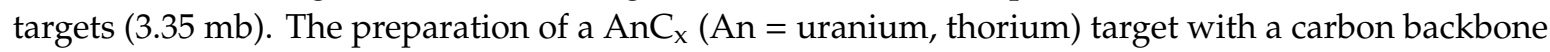
from molecule of diphtalocyanine has also been reported [10]. The final product was a highly porous, brittle and granular material. Its metal content was $\sim 30-50$ weight $\%$, with the metal atoms being isotropically distributed inside the carbon matrix. The target, which has low density, $1.1-1.3 \mathrm{~g} / \mathrm{cm}^{3}$, and a low content of the metal atoms (18-20 carbon atoms per metal atom), did not sinter even after $100 \mathrm{~h}$ at $2573 \mathrm{~K}$, probably due to the high carbon concentration.

$\mathrm{UC}_{\mathrm{x}}$ targets for the SPIRAL 2 and ALTO projects were described by Bajeat et al., with aim to more than $10^{13}$ fissions/s with a good release time, but it was difficult to keep the targets at high temperatures $(>2273 \mathrm{~K}$ ) for long periods of time [11]. Target disks around $1 \mathrm{~mm}$ thick, composed of graphite-embedded $20 \mu \mathrm{m}-30 \mu \mathrm{m}$ grains of uranium carbide were manufactured by compressing a mixture of uranium oxide and graphite powders. These were heated it at $2273 \mathrm{~K}$ under vacuum for carboreduction by the following reactions:

$$
\begin{aligned}
& \mathrm{UO}_{2}+6 \mathrm{C} \rightarrow \mathrm{UC}_{2}+2 \mathrm{C}+2 \mathrm{CO} \\
& \mathrm{UO}_{2}+6 \mathrm{C} \rightarrow \mathrm{UC}+3 \mathrm{C}+2 \mathrm{CO}
\end{aligned}
$$

It was observed that excess graphite limits the grain size of uranium carbides and minimizes the diffusion paths. Release of $\mathrm{Cs}$ and $\mathrm{Rb}$ were reported to be better from such low-density carbide targets than from high-density ones. However, Lhersonneau et al. [12] described in a review on the performance of high-density $\mathrm{UC}_{\mathrm{x}}$ targets with grain sizes of $\sim 200 \mu \mathrm{m}$, developed in the IRIS facility at Gatchina (Russia), that they show an excellent Cs and Rb production performance, with a yield higher than the low-density, $25 \mu \mathrm{m}-35 \mu \mathrm{m}$ targets in use at PARRNe-Orsay. Nevertheless, a slower release was observed, which was surpassed by new, high-density, $\mathrm{UC}_{\mathrm{x}}$ materials with grain sizes of $\sim 20 \mu \mathrm{m}$. Uranium carbide target materials with $5 \mu \mathrm{m}$ and $20 \mu \mathrm{m}$ grain sizes were prepared by powder metallurgy [13]. They were tested online between $2073 \mathrm{~K}$ and $2373 \mathrm{~K}$, showing a Fr production yield very close for both materials, whereas for the Cs production the $5 \mu \mathrm{m}$ grain target displayed a yield approximately 3 times higher than the $20-\mu \mathrm{m}$ grain target. All these studies corroborated the convenience of using small grain size materials for ISOL targets.

A thorough study including nano-grained $\mathrm{UC}_{\mathrm{x}}$ materials production for ISOL targets was undertaken within the CERN-MEDICIS project [14]. Its main objective was to increase the RIBs 
intensity by two or three orders of magnitude. In the light of the reasoning reported above, such an ambitious goal can be achieved not only by preparing chemically suited target materials, but also by keeping the grain sizes in the nanometric size, even at high working temperatures. However, conventional preparation methods of target materials lead to final morphologies where the grains can easily grow along the 3 directions ( $x, y$, and $z$ ). Therefore, the development of innovative target material preparation methods, which would minimize the grain growth, or at least allow the target material to evolve only along one of the directions, is highly desirable. One possible approach of this kind can consist of the development of target materials in the form of fibers or, more specifically, micro- or nanofibers. In this case, the $\mathrm{x}$ and $\mathrm{y}$ dimensions are in the $\mu \mathrm{m}$ or $\mathrm{nm}$ scale, while the $\mathrm{z}$ dimensions can be much larger. A high porosity and a large surface-to-volume ratio in the fiber-based materials can result in a quick release of radioisotopes [15]. Fibers are obtained from polymers, their entanglement properties allowing the preparation of very long and thin samples. The diameter of the polymer fiber are in the $\mu \mathrm{m}-\mathrm{nm}$ scale, with few contact points between them that inhibit the rapid growth and sintering at high temperatures, and, at the same time, foster in-grain isotope diffusion. Moreover, this approach permits to know the carbon and metal content in the fiber samples, offering a good control over the core density. Elemental C can be produced during the pyrolysis of a polymer $[16,17]$, resulting in an excess of carbon in the fibers. This gives improved mechanical stability and high thermal conductivity $[18,19]$. The excess of carbon also inhibits grain growth and coalescence of neighboring grains [16]. Nuclear ceramic materials have been successfully prepared from polymers using the polymer infiltration and pyrolysis method [20]. There are several techniques to obtain such kind of fiber samples containing f-block elements, e.g., drawing [21], template synthesis [22], phase separation [23], self-assembly [24], and electrospinning [25]. The first four techniques are time-consuming and require the control of numerous factors (e.g., viscoelastic stress, electrical conducting properties, and dissolution). Electrospinning is a top-down technique based on the electrospinning of a polymer in solution [26] that has been used in the mass production of long, continuous, fibers [25]. In the electrospinning process, a high voltage between two electrodes is used to generate a charged jet of a polymer solution (that can contain metal(s) ion(s)) out of a needle orifice. Without any voltage the solution is held by its surface tension at the tip of a needle, which also constitutes one of the electrodes. When high voltage is applied between the needle and the collector (the other electrode), the solution is submitted to a high electric field and an induction charge appears on the surface of the liquid. A hemispherical shape is formed at the tip of the needle due to the mutual charge repulsion, which acts oppositely to the surface tension. With increasing voltage, the hemispherical surface elongates and transforms into a cone, known as the Taylor Cone [27]. By further increasing the electric field, a critical value is reached, where the repulsive force overcomes the surface tension and the fluid jet is ejected from the tip of the Taylor cone. After the polymer solution discharging, a bending instability followed elongation process occurs. On the way to the collector, the solvent evaporates and solid fibers are recovered.

This work is focused on the electrospinning preparation of uranium carbide fibers, with micrometer diameter but composed of nanometer size grains. Polymeric fibers with uranium salts were prepared by the electrospinning technique, and subsequently heat-treated in two steps. A first stage, until $823 \mathrm{~K}$, was aimed at decomposing the base polymer, and a second step, at $2073 \mathrm{~K}$ promoted the carboreduction reaction. The materials obtained after each of these steps were characterized in terms of crystal structure, morphology, grain size, and composition.

\section{Materials and Methods}

The experimental section is divided into three sub-sections. In the first, the preparation of the viscous solutions with uranium precursor salts dissolved is briefly explained. In the second, the electrospinning production of fibers from the viscous solutions is described; in addition, heat treatments of the as spun fibers at medium temperatures (to decompose the polymer) and 
at high temperatures (to promote the carboreduction of the $\mathrm{UO}_{2}$ ) are discussed thoroughly. Finally, the last sub-section depicts the characterization techniques employed to study the fiber samples.

\subsection{Preparation of the Viscous Solution with the Uranyl Precursors}

Uranium (primary isotope ${ }^{238} \mathrm{U}$ ) is a weak $\alpha$-emitter $(4.197 \mathrm{MeV})$ with a half-life of $4.47 \times 10^{9}$ years. Manipulations and reactions should be carried out in monitored fume hoods in a radiation laboratory equipped with $\alpha$ - and $\beta$-counting equipment. Three different uranium precursor salts have been used, namely uranyl acetylacetonate, uranyl acetate, and uranyl formate. Uranyl acetylacetonate can be prepared by the slow addition of aqueous sodium hydroxide to solutions containing uranyl nitrate and acetylacetone, while uranyl formate is obtained from uranyl nitrate solutions with an excess of formic acid [28,29]. Uranyl acetate is commercially available (Merck, Darmstadt, Germany), but can also be prepared by reacting $\mathrm{UO}_{3}$ with acetic acid [30]. The cellulose acetate polymer (Sigma-Aldrich, St. Louis, Missouri, USA, no purity info, average Mn $\sim 50,000$ by GPC) was first dissolved in a a:b ( $v / v$ ) acetic acid (PanReac, Barcelona, Spain, Acetic Acid glacial, 99.5\%) and 2,4-pentanedione solution (Fluka Chemie AG, Buchs, Switzerland, acetylacetone p.a.) at $333 \mathrm{~K}$ under magnetic stirring conditions (a:b $=1: 2$ for the case of uranyl acetate and 1:1 for uranyl acetylacetonate and uranyl formate precursors). After the cellulose acetate dissolution, the uranium precursor salt was added to the solution in three different $\mathrm{U} / \mathrm{C}$ mole ratios, $1 / 2,1 / 4$, and $1 / 6$, taking into account the polymer matrix and uranyl anions. The mixture was stirred until all uranyl salt was completely dissolved, with the final volume of the solution being adjusted to a polymer concentration of $10,12.5$, or 15 weight $\%$ by adding or evaporating the solvent (which was controlled by weighting). After that, the viscous solutions were ready to be electrospun.

\subsection{Preparation and Heat-Treatment of the Fibers}

There are three components in an electrospinning system namely (i) a high voltage power supply, (ii) a pump with a syringe containing a metallic needle with small diameter, and (iii) a metal collector. The syringe filled with the viscous solution was placed on the pump and the liquid was ejected with a rate between $0.8-2.5 \mathrm{~mL} / \mathrm{h}$. A high voltage of $18-30 \mathrm{kV}$ was used to generate a charged jet of polymer solution out of the needle orifice, which was recovered in an aluminum-foil collector placed at $\sim 12 \mathrm{~cm}$ away from the needle tip. The as-spun fibers were then heated to $823 \mathrm{~K}$ at $1 \mathrm{~K} / \mathrm{min}$ heating rate inside a tubular furnace under an argon gas flow atmosphere. After that, the decomposed material was inserted into a carbon glass crucible, which was placed inside an induction furnace chamber that was vacuum pumped. Once the $2 \times 10^{-6} \mathrm{mbar}$ pressure has been reached, the heat treatment started. The temperature was increased under vacuum (not letting surpass $2 \times 10^{-5}$ mbar) to promote the carbo-thermal reaction and the extraction of the $\mathrm{CO}$ produced. At the end, the decomposed material was heated at $2073 \mathrm{~K}$ for $2 \mathrm{~h}$.

\subsection{Characterization}

The morphology and chemical compositions of the as-spun fibers and heat-treated materials were studied using optical, scanning and transmission electron microscopy (SEM and TEM respectively). SEM observations were made using a JEOL 7001F microscope (JEOL Ltd., Tokyo, Japan) operating at $20 \mathrm{kV}$, with Oxford light elements EDS detector (Oxford Instruments, Concord, MA, USA), and a Hitachi S2400 system (Hitachi, Tokyo, Japan) working at $15 \mathrm{kV}$, with Bruker light elements EDS detector (Bruker Corporation, Billerica, MA, USA). A TecnaiG2 TEM $200 \mathrm{kV}$ with an EDS analysis system and a high-angle annular dark-field (HAADF) detector for scanning transmission electron microscope (STEM) imaging (Thermo Fisher Scientific, Eindhoven, The Netherlands), equipped with a Gatan ${ }^{\mathrm{TM}}$ Tridiem GIF camera (Gatan, Pleasanton, CA, USA), was used to characterize the crystallite sizes and morphology. The samples were prepared by crushing tiny fragments of the various compounds in methanol. The suspension was allowed to decant, and a droplet was subsequently deposited on a copper grid coated with carbon. 
Heat-treated samples were manually crushed in a mortar grinder, the resulting powder was placed onto a low-noise Si single crystal sample holder and studied by powder X-ray diffraction (XRD). XRD measurements were performed in a PANalytical X'Pert-Pro diffractometer (PANalytical Co., Almelo, Holland, $\mathrm{Cu} \mathrm{K}_{\alpha}$-radiation) with Bragg-Brentano geometry. Step-scanning mode XRD patterns were taken in the $10-100^{\circ} 2 \theta$ region using the $\theta / 2 \theta$ configuration, a step size of $0.04^{\circ}$ and a counting time of $40 \mathrm{~s}$ per step. The theoretical powder patterns were simulated with the help of the Powder-Cell software [31] and the lattice parameters were calculated by using the UnitCell software [32].

Thermogravimetry analysis (TGA) of the electrospun material was performed from room temperature up to $873 \mathrm{~K}$ using a Dupont 951 Thermo-Gravimetric Analyser (TA Instruments, New Castle, PA, USA) equipped with a Temperature Programmer Interface TA Controller System. The measurements were carried out under nitrogen, with a constant flux of $50 \mathrm{~mL} / \mathrm{min}$ and a heating rate of $10 \mathrm{~K} / \mathrm{min}$.

Raman spectra were collected with a Jobin-Yvon ${ }^{\circledR}$ T64000 spectrometer (HORIBA JobinYvon, Longjumeau, France) used in the single spectrograph configuration. The $647 \mathrm{~nm}$ line of a $\mathrm{Kr}^{+}$ Coherent ${ }^{\circledR}$ laser was used as an excitation source, with a nominal power at the laser cavity of $100 \mathrm{~mW}$. This wavelength and power were chosen in order to optimize the signal/noise ratio and reduce undesirable oxidation/burning effects on the sample surface [33]. The Raman spectrograph was calibrated with the $\mathrm{T}_{2 \mathrm{~g}}$ excitation line of a silicon single crystal, set at $520.5 \mathrm{~cm}^{-1}$ [34]. Raman spectra were recorded with an instrumental uncertainty of $\pm 1 \mathrm{~cm}^{-1}$.

\section{Results and Discussions}

The feasibility of the precursor fibers formation as a function of the cellulose acetate polymer concentration, determined by optical microscopy observation, is shown in Table 1 for the three different uranyl salts. The quality of as-spun uranium-containing fibers strongly depends on the amount of the polymer present in the viscous solution, as the polymer entanglement property can keep the fibers continuous during their migration from the needle tip to the collector. Concurrently, the solvent evaporates and dry fibers can be collected on the aluminum-foil collector.

Table 1. Feasibility of precursor fibers formation for the three different concentrations of cellulose acetate polymer, along with the various uranyl salts.

\begin{tabular}{cccc}
\hline Salt Polymer Weight (\%) & Uranyl Acetate & Uranyl Acetylacetonate & Uranyl Formate \\
\hline 10 & No & No & No \\
12.5 & Yes & Yes & Yes \\
15 & Yes & Yes & Yes \\
\hline
\end{tabular}

SEM observations confirmed the optical microscopy results. For the $10 \%$ weight concentration of cellulose acetate polymer, the spun material consists on solidified drops for any of the applied voltages and uranyl salts. The formation of continuous fibers is inhibited for low polymer concentrations due to the lack of viscosity of the solution, resulting in the formation of droplets, which can be connected by very thin fibers (average diameter of $\sim 0.1 \mu \mathrm{m}$ ), along with beads (Figure 1a,b). The solidified droplets are concave in shape and can have one or more holes. Increasing the cellulose acetate concentration, and for voltages between 18 and $22 \mathrm{kV}$, a web consisting of beads interconnected by $\sim 1 \mu \mathrm{m}$ diameter fibers is formed, as can be seen for the $12.5 \%$ weight concentration (Figure 1c,d). At higher concentrations of cellulose acetate polymer, i.e., 15\%, the fibers obtained from electrospinning are of good quality in the 18-30 kV voltage range for all uranyl salts, but the uranyl acetate gives fibers of better quality. The fibers obtained are thin, with diameters ranging from 0.5 to $2 \mu \mathrm{m}$ and a smooth surface, without beads and droplets, as shown in Figure 1e-g. Above the 15\% concentration, the solution becomes too viscous to be electrospun. 

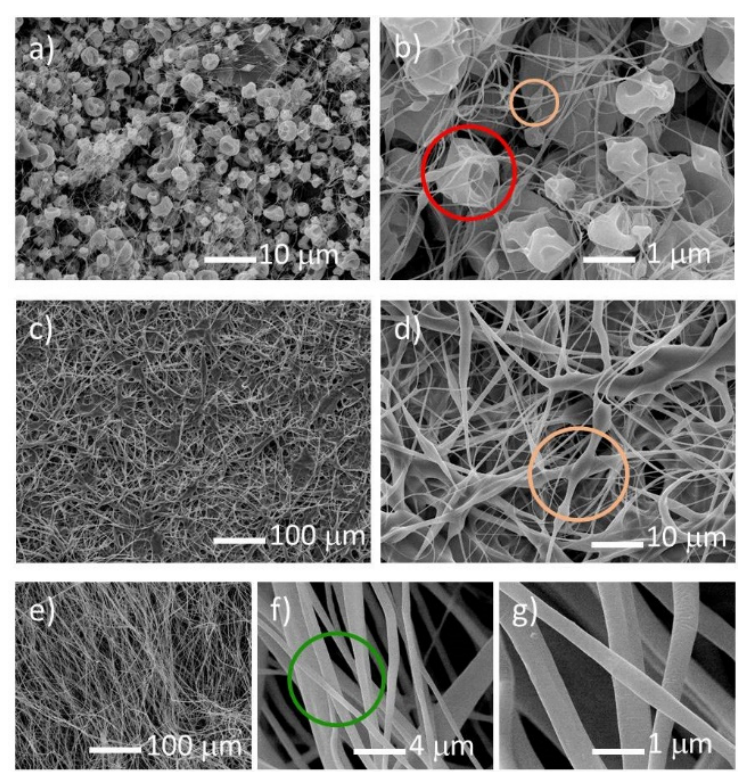

Figure 1. Scanning electron microscopy images of uranyl acetate as-spun fibers with $U / C=1 / 6$ and a cellulose acetate polymer weight concentration of $10 \%(\mathbf{a}, \mathbf{b}), 12.5 \%(\mathbf{c}, \mathbf{d})$, and $15 \%(\mathbf{e}-\mathbf{g})$.

TGA results for cellulose acetate and the as-spun fibers of uranyl salts (acetate (ac), acetylacetonate (acac) and formate) are shown in Figure 2. Three distinct weight loss stages can be identified in all precursor fibers. At the beginning, from room temperature to $\sim 333 \mathrm{~K}$, the weight loss is $\sim 6 \%$ for all samples, which is mainly due to solvents evaporation. Next, a flat plateau is seen, until $\sim 503 \mathrm{~K}$ for the uranium materials and $\sim 613 \mathrm{~K}$ for the cellulose acetate polymer. Between $\sim 503 \mathrm{~K}$ and $\sim 573 \mathrm{~K}$ a second weight loss drop, corresponding to more than $50 \%$ decrease, is observed for uranyl acetylacetonate and uranyl formate precursor fibers. In the case of uranyl acetate, this drop also exists, but at higher temperatures, between $\sim 523 \mathrm{~K}$ and $\sim 633 \mathrm{~K}$, while for cellulose acetate it goes from $\sim 613 \mathrm{~K}$ to $\sim 663 \mathrm{~K}$. This large weight decrease is due to the decomposition reaction, where the uranyl salts and cellulose acetate are converted mainly into uranium oxide, $\mathrm{UO}_{2}$, and graphite, $\mathrm{C}$ (see SEM/EDS and XRD results below). The higher decomposition temperature of the uranyl acetate precursor is probably due to the presence of strong interactions between the acetate groups of cellulose acetate and uranyl salt. Thereafter, no further decomposition was noticed for the cellulose acetate polymer, but a smooth weigh decrease, which corresponds to the decomposition of the remaining organics, with the formation and subsequent evaporation of volatile compounds, was observed for the uranium materials. In this stage, the loss is more pronounced for the uranyl formate fibers, which can be attributed to the volatile nature of the formate ligands. This last step corresponds to a weight loss of $\sim 10 \%$ and finishes at $\sim 793 \mathrm{~K}$.

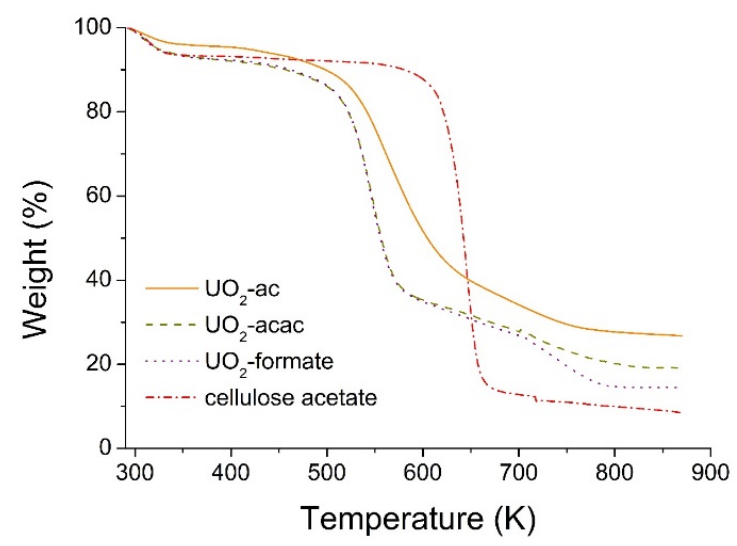

Figure 2. Thermal gravimetric curves of cellulose acetate, and the uranyl salts as-spun fibers with $\mathrm{U} / \mathrm{C}=1 / 4$ and a cellulose acetate weight concentration of $15 \%$. 
Following the electrospinning procedure and with the data obtained from TGA, the as-spun fibers were decomposed in a tubular furnace. The fibers were inserted in the furnace that was first settled at $296 \mathrm{~K}$, and then heated with a rate of $1 \mathrm{~K} / \mathrm{min}$ up to $823 \mathrm{~K}$ in a steady argon-gas flow. The release of smoke-type gases was observed, the decomposition being considered complete when the gas release stopped. With this procedure, it was possible to retain the fiber morphology after the heat treatment (Figure 3a-c). In contrast, if the fibers were heated rapidly, the polymer melted before the decomposition and the original shape was lost. A significant decrease of the fibers diameter is observed, which accounts for the large weight loss indicated by TGA. EDS analysis indicated that the decomposed material is constituted by uranium, carbon, and oxygen.
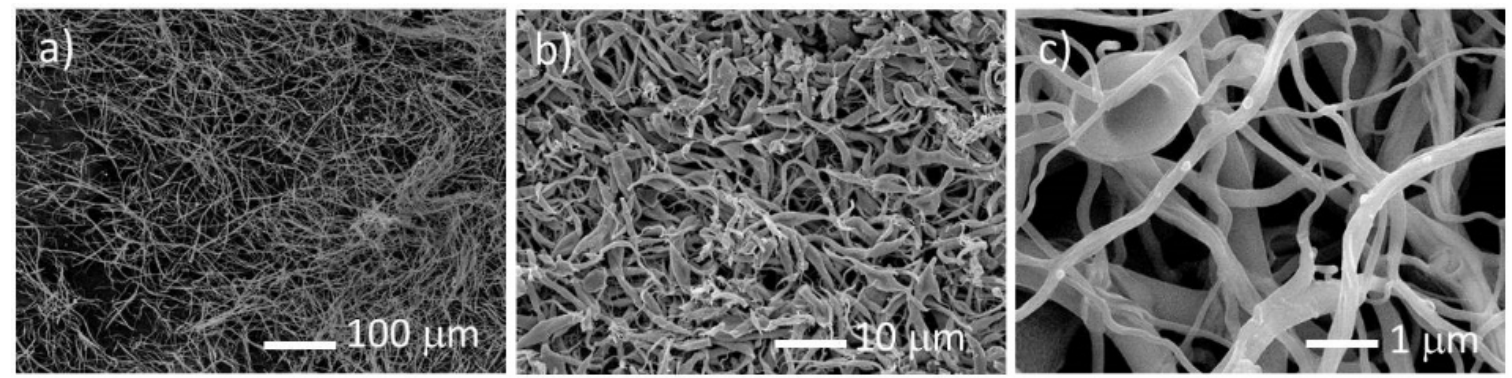

Figure 3. Scanning electron microscopy images of the decomposed fibers of (a) uranyl acetate, (b) uranyl formate, and (c) uranyl acetylacetonate salts with $15 \%$ cellulose acetate weight concentration and U/C $=1 / 6$ after heat treated at $823 \mathrm{~K}$.

The decomposed material was further heated under vacuum at $2073 \mathrm{~K}$ for $2 \mathrm{~h}$, to promote the uranium oxide carboreduction. The final material is composed of highly porous and uncompact fibers, as shown in Figure 4.

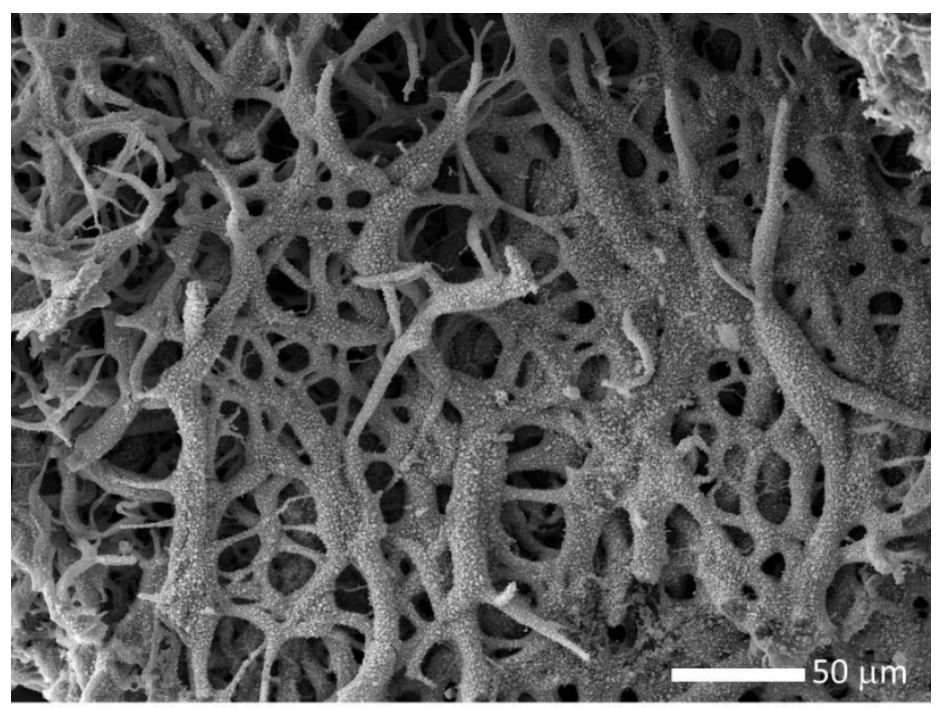

Figure 4. Scanning electron microscopy image of the fibers heat treated at $2073 \mathrm{~K}$ for $2 \mathrm{~h}$ of the decomposed fibers of uranyl acetate salt with cellulose acetate polymer concentration $(w / v) 15 \%$ of $\mathrm{U} / \mathrm{C}=1 / 4$.

The pores may form due to inward carboreduction reactions that release carbon oxide gases. EDS analysis indicate that the carbo-reduced material contains uranium, oxygen, and carbon in excess (>60 in atomic \%), which points to an uncompleted carboreduction reaction.

X-ray patterns of the decomposed and heated at $2073 \mathrm{~K}$ samples are presented in Figure 5a,b. The fibers decomposed at $823 \mathrm{~K}$ are mainly constituted by uranium dioxide, the $\mathrm{a}=5.430(1) \AA$ small lattice parameter pointing to a hyperstoichiometric oxygen composition [35]. Carbon is also present, 
but its small electron density and the possible existence of disorder only allowed the detection of its most intense peak. The $\mathrm{UO}_{2+x}$ peaks are very broad, indicating a nanocrystalline character of the decomposed fibers. The material heat treated at $2073 \mathrm{~K}$ for $2 \mathrm{~h}$ has the tetragonal $\mathrm{UC}_{2-\mathrm{y}}$ as the major phase, but $\mathrm{UO}_{2+\mathrm{x}}$ still exists in a moderate concentration ( $\left.30 \mathrm{vol} . \%\right)$, which points to the uncompleted carboreduction reaction and agrees with the EDS results.
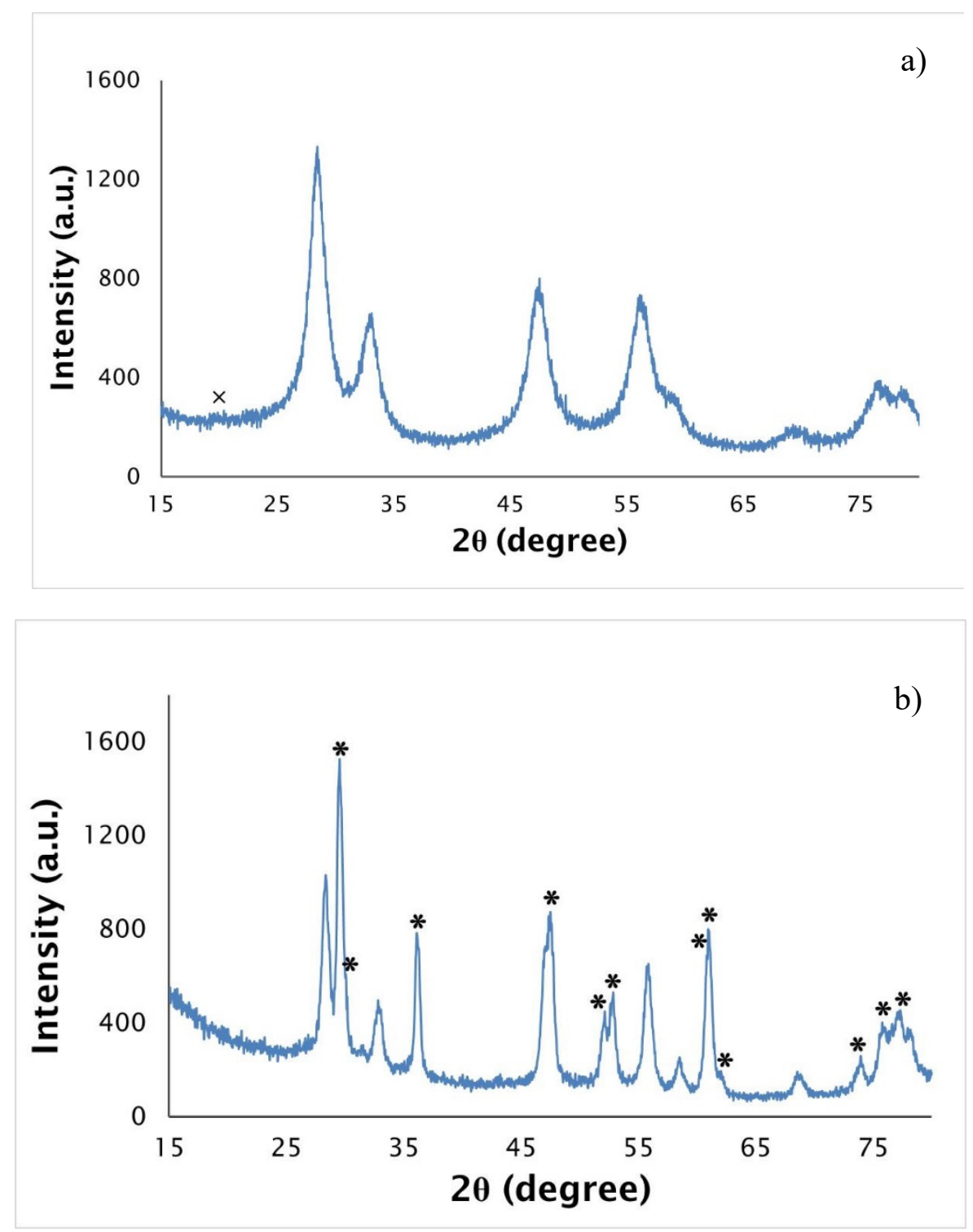

Figure 5. X-ray diffractograms of the uranyl acetate as-spun fibers with $\mathrm{U} / \mathrm{C}=1 / 4$ and a cellulose acetate polymer weight concentration of $15 \%$ after (a) decomposed at $823 \mathrm{~K}$ and (b) after heat treated at $2073 \mathrm{~K}$ for $2 \mathrm{~h}$ (crosses-carbon, stars- $\mathrm{UC}_{2}$, unmarked peaks- $\mathrm{UO}_{2}$ ).

An increase of the $\mathrm{UO}_{2+x}$ lattice parameter is observed $(\mathrm{a}=5.457(1) \AA)$ together with an increase of the sharpness of the uranium oxide peaks, pointing to a decrease of the hyperstoichiometry and increase of crystallinity. The $U_{2}$-y lattice parameters $(a=3.5144(3) \AA, a=5.970(1) \AA)$ are in agreement with published data [36]. The incomplete carboreduction reaction can be partially explained by the excess of carbon that impedes the atoms diffusion. However, it is expected that longer heat treatments would allow the total oxide carboreduction into uranium dicarbide.

Transmission electron microscopy (TEM) images of the decomposed fiber and carbo-reduced material are shown in Figure 6a,b. The decomposed material is nanocrystalline, with average grain 
sizes below $10 \mathrm{~nm}$, being composed of uranium oxide and carbon, which supports the X-ray diffraction results. TEM observations also reveal that in the decomposed fibers the uranium oxide nano-particles are embedded in a graphite matrix. After the heat-treatment, most of the uranium oxide was reduced to uranium dicarbide, which has particle sizes in the range $4 \mathrm{~nm}-10 \mathrm{~nm}$.
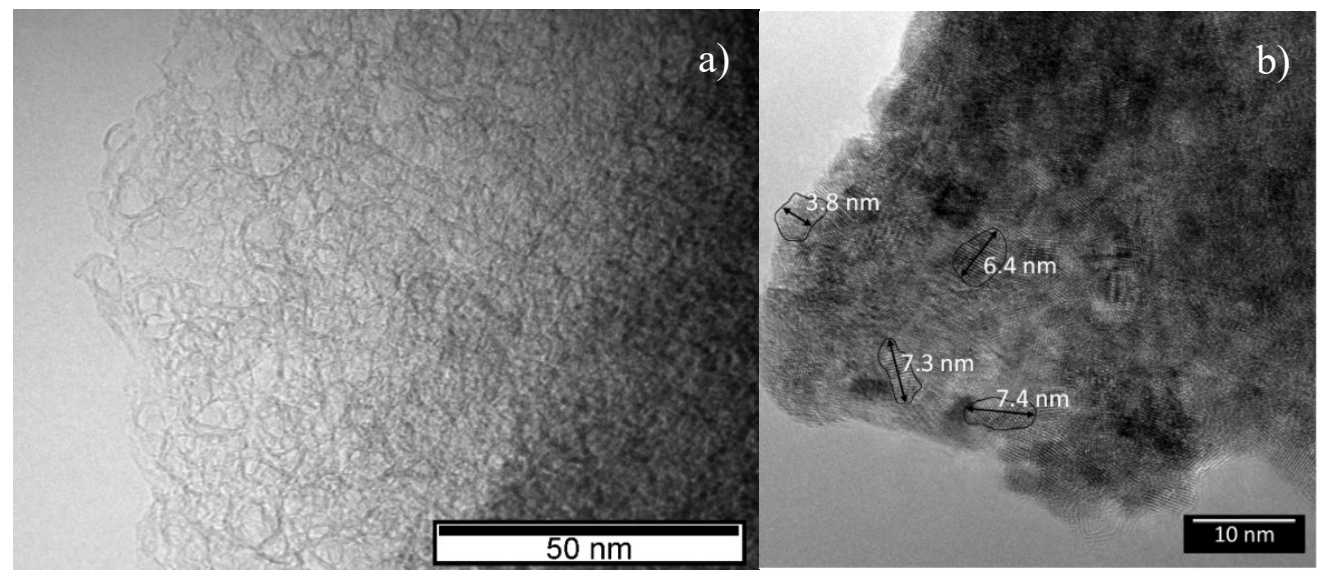

Figure 6. Transmission electron microscopy images of the uranyl acetate as-spun fibers with U/C $=1 / 4$ and a cellulose acetate polymer weight concentration of $15 \%$ after (a) decomposed at $823 \mathrm{~K}$ and (b) after heat treated at $2073 \mathrm{~K}$ for $2 \mathrm{~h}$.

Raman spectroscopy studies have been carried out on the final carbo-reduced material. A representative spectrum is shown in Figure 7.

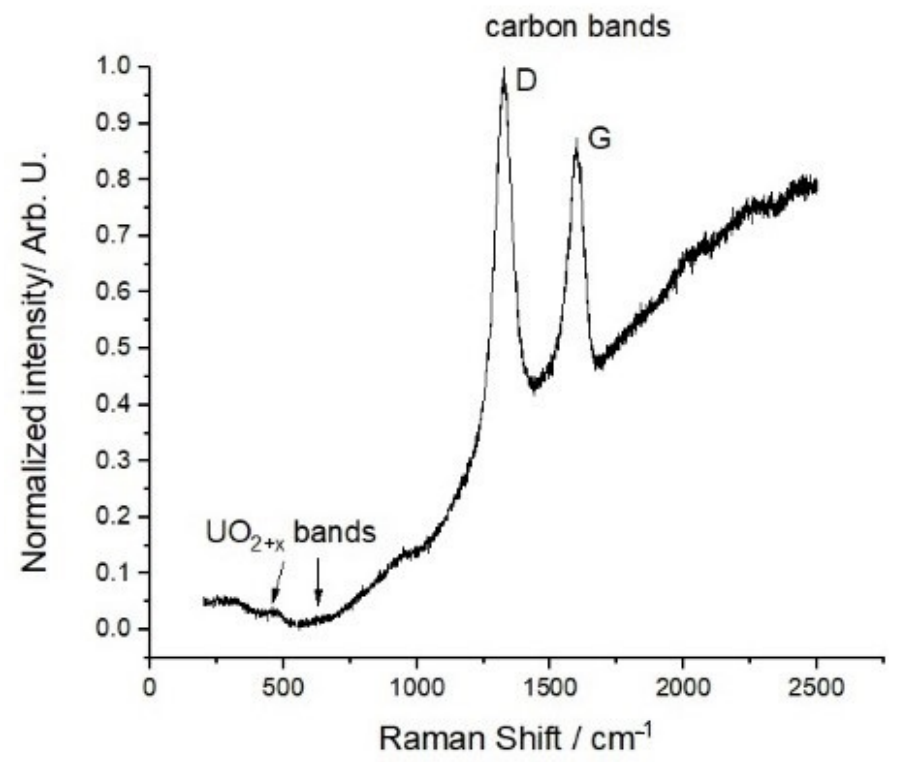

Figure 7. Raman spectrum of the uranyl acetate as-spun fibers with $\mathrm{U} / \mathrm{C}=1 / 4$ and a cellulose acetate polymer weight concentration of $15 \%$ after heat treated at $2073 \mathrm{~K}$ for $2 \mathrm{~h}$.

The spectrum displays no clear features at energies below $1000 \mathrm{~cm}^{-1}$. Yet, one can spot Raman bands related to the presence of moderate amounts of $\mathrm{UO}_{2+x}\left(\right.$ at $445 \mathrm{~cm}^{-1}, 575 \mathrm{~cm}^{-1}$, and $630 \mathrm{~cm}^{-1}$ [35]). However, they are rather blurred and probably close to the current intensity detection limits. Two large peaks are observed in the spectrum at higher wave numbers, the first being located at $\sim 1320 \mathrm{~cm}^{-1}$ and the second at $\sim 1590 \mathrm{~cm}^{-1}$. As no Raman active peaks exist for uranium dicarbide, the observed ones can only be due to carbon. Disordered and ordered graphite display D and G bands, located at $\sim 1350 \mathrm{~cm}^{-1}$ and $\sim 1580 \mathrm{~cm}^{-1}$, respectively [37]. The $\mathrm{G}$ band is originated from the $\mathrm{E}_{2 \mathrm{~g}}$ vibration of ordered graphite, 
corresponding to the relative motion between two $\mathrm{sp}^{2}$ carbon atoms. The $\mathrm{D}$ band is due to the $\mathrm{A}_{1 \mathrm{~g}}$ breathing modes of $\mathrm{sp}^{2}$ ring atoms. This Raman-active vibration is symmetrically forbidden for a perfect graphite crystal, but becomes quite intense in a defective lattice. Comparison with the present results indicates that the first peak corresponds to the $\mathrm{D}$ band, while the second is certainly linked to the $G$ band. The energy shifts observed in the peak positions with respect to the nominal values expected for pure graphite are attributable to the specific morphology and chemical environment of the present materials. The higher intensity of the $\mathrm{D}$ band confirms the existence of considerable disorder in the graphite, as was already suggested by the X-ray diffraction results.

\section{Conclusions}

Uranium carbide fibers with micrometer diameters and nanometer grain sizes were successfully synthesized from viscous solutions of cellulose acetate and uranyl salts using (i) the electrospinning method, followed by (ii) subsequent decomposition by slow heating up to $823 \mathrm{~K}$ under argon and (iii) carboreduction at $2073 \mathrm{~K}$ under vacuum for $2 \mathrm{~h}$.

Good quality precursor fibers, with diameters ranging from 0.5 to $2 \mu \mathrm{m}$ and smooth surfaces, were obtained for all uranyl salts solutions having 15\% weight concentrations of cellulose acetate, indicating that a critical factor for the fibers formation is the polymer concentration, although the best ones were achieved from the solutions containing uranyl acetate. A slow heating rate, of $1 \mathrm{~K} / \mathrm{min}$, during the decomposition step allowed to retain the fiber morphology up to high temperature, the samples being composed by $\mathrm{UO}_{2}$ and $\mathrm{C}$ with average grain sizes below $10 \mathrm{~nm}$. The release of volatile compounds and crystallization during the decomposition process lead to a decrease of the fibers diameter and the formation of such nanostructured material. The high-temperature heat treatment at $2073 \mathrm{~K}$ promotes the carboreduction of $\mathrm{UO}_{2}$ to $\mathrm{UC}_{2-\mathrm{y}}$ while keeping the grain sizes in the $4 \mathrm{~nm}-10 \mathrm{~nm}$ range, but the reaction was not completed after $2 \mathrm{~h}$, with a moderate volume concentration of oxides still existing. A carbon excess and the fibers morphology, which hinders the atoms diffusion due to the small number of contact points between the carbon and uranium oxide grains, are probably the reason for such incomplete carboreduction. However, longer heat treatments are expected to induce a total carboreduction of the oxide into uranium dicarbide.

The first preliminary online tests of the uranium carbide fiber materials are expected to be performed at ISOLDE, after the CERN Long Shutdown 2, scheduled for the middle of 2021.

Author Contributions: Conceptualization, T.S. and A.P.G.; Funding acquisition, T.S. and A.P.G.; Investigation, S.C., L.M., A.C., D.M., O.D.-B., and A.P.G.; Methodology, A.P.G.; Resources, D.M. and A.P.G.; Supervision, A.P.G.; Writing—original draft, S.C.; Writing—review and editing, L.M., D.M., and A.P.G. All authors have read and agreed to the published version of the manuscript.

Funding: This work was partially funded by a Marie Skłodowska-Curie Innovative Training Network Fellowship of the European Commission's Horizon 2020 Programme under contract number 642889 MEDICIS-PROMED, and by the Fundação para a Ciência e a Tecnologia (FCT) through the projects UID/Multi/04349/2019 and UIDB/00100/2020, and the contract number IST-ID/091/2018 (L.M.). The material characterisation campaign performed at JRC- Karlsruhe was supported by the EC Actinide User Lab (AUL-189/ARES (2017) 2686329) project.

Acknowledgments: The Authors are indebted to R. Konings and T. Wiss for their advice, and to J.-Y. Colle for his help with the Raman measurements.

Conflicts of Interest: The authors declare no conflict of interest.

\section{References}

1. Stolarz, A. Target preparation for research with charged projectiles. J. Radioanal Nucl. Chem. 2013, 299, 913-931. [CrossRef]

2. Stora, T.; Fernandes, S.; Mathot, S.; Bowen, P. Nanostructured Target for Isotope Production. European Patent EP2342952A1, 13 July 2011.

3. Gottberg, A. Target material for exotic ISOL beams. Nucl. Instrum. Methods Phys. Res. B 2016, 376, 8-15. [CrossRef] 
4. Ravn, H.L.; Allardyce, B.W. On-Line Mass Separators. In Treatise on Heavy-Ion Science; Bromley, D.A., Ed.; Plenum Press: New York, NY, USA, 1989; pp. 363-442.

5. Biasetto, L.; Zanonato, P.; Carturan, S.; Di Bernardo, P.; Colombo, P.; Andrighetto, A.; Prete, G. Developing uranium dicarbide-graphite porous materials for the SPES project. J. Nucl. Mater. 2010, 404, 68-76. [CrossRef]

6. Dos Santos Augusto, R.M.; Buehler, L.; Lawson, Z.; Marzari, S.; Stachura, M.; Stora, T.; CERN-MEDICIS Collaboration. CERN-MEDICIS (Medical Isotopes Collected from ISOLDE): A New Facility. Appl. Sci. 2014, 4, 265-281. [CrossRef]

7. Crane, J.; Kalish, H.S.; Litton, F.B. The Development of Uranium Carbide as a Nuclear Fuel; Technical Information Service, 3rd Annual Report; United States Atomic Energy Commission: Washington, DC, USA, 1963.

8. Hagebø, E.; Hoff, P.; Omtvedt, J.P.; Steffensen, K.; Jonsson, O.C.; Kugler, E.; Ravn, H.L. New production systems at ISOLDE. Nucl. Instrum. Methods Phys. Res. B 1992, 70, 165-174. [CrossRef]

9. Evensen, A.H.M.; Catherall, R.; Drumm, P.; Van Duppen, P.; Jonsson, O.C.; Kugler, E.; Lettry, J.; Tengblad, O.; Tikhonov, V.; Ravn, H.L.; et al. Release and yields from thorium and uranium targets irradiated with a pulsed proton beam. Nucl. Instrum. Methods Phys. Res. B 1997, 126, 160-165. [CrossRef]

10. Bolshakov, V.A.; Dernyatin, A.G.; Mezilev, K.A.; Novikov, Y.N.; Polyakov, A.G.; Popov, A.V.; Sergeev, Y.Y.; Tikhonov, V.I. The production of neutron-rich heavy nuclei of astrophysical interest at the IRIS facility. Nucl. Instrum. Methods Phys. Res. B 1992, 70, 69-74. [CrossRef]

11. Bajeat, O.; Mhamed, M.C.; Essabaa, S.; Huguet, Y.; Ibrahim, F.; Lau, C.; Lecesne, N.; Leherrissier, P.; Leroy, R.; Mirea, M.; et al. $\mathrm{UC}_{\mathrm{x}}$ target developments for the ALTO and the SPIRAL 2 projects. Nucl. Instrum. Methods Phys. Res. A 2006, 562, 634-637. [CrossRef]

12. Lhersonneau, G.; Alyakrinskiy, O.; Bajeat, O.; Barzakh, A.E.; Dubois, M.; Eléon, C.; Essabaa, S.; Fedorov, D.V.; Gaubert, G.; Ionan, A.M.; et al. Tests of high-density UC targets developed at Gatchina for neutron-rich radioactive-beam facilities. Nucl. Instrum. Methods Phys. Res. B 2008, 266, 4326-4329. [CrossRef]

13. Panteleev, V.N.; Alyakrinskiy, O.; Barbui, M.; Barzakh, A.E.; Fedorov, D.V.; Ivanov, V.S.; Lhersonneau, G.; Mezilev, K.A.; Molkanov, P.L.; Moroz, F.V. Production of Cs and Fr isotopes from a high-density UC targets with different grain dimensions. Eur. Phys. J. A 2009, 42, 495-501. [CrossRef]

14. Cocolios, T.E.; Ferrari, C.; Reid, F.; Stora, T. MEDICIS-Promed: An Innovative Training Network for a new generation of professionals in nuclear medicine. In EMBEC \& NBC 2017, Proceedings of the IFMBE, Tampere, Finland, 11-15 June 2017; Eskola, H., Väisänen, O., Viik, J., Hyttinen, J., Eds.; Springer: Singapore, 2018; Volume 65, pp. 530-533.

15. Hy, B.; Barré-Boscher, N.; Özgümüs, A.; Roussiere, B.; Tusseau-Nenez, S.; Lau, C.; Mhamed, M.C.; Raynaud, M.; Said, A.; Kolos, K. An off-line method to characterize the fission product release from uranium carbide-target prototypes developed for SPIRAL2 project. Nucl. Instrum. Methods Phys. Res. B 2012, 288, 34-41. [CrossRef]

16. Ferry, J.D. Viscoelastic Properties of Polymers, 3rd ed.; John Willey \& Sons: New York, NY, USA, 1980.

17. Chand, S. Review Carbon fibers for composites. J. Mater. Sci. 2000, 35, 1303-1313. [CrossRef]

18. Koster, U.; Bergmann, U.C.; Carminati, D.; Catherall, R.; Cederkall, J.; Correia, J.G.; Crepieux, B.; Dietrich, M.; Elder, K.; Fedoseyev, V.N.; et al. Oxide fiber targets at ISOLDE. Nucl. Instrum. Methods Phys. Res. B 2003, 204, 303-313. [CrossRef]

19. Praderea, C.; Batsalea, J.C.; Goyhénècheb, J.M.; Paillerb, R.; Dilhairec, S. Thermal properties of carbon fibers at very high temperature. Carbon 2009, 47, 737. [CrossRef]

20. Zhang, H. Novel Processing of Unique Ceramic-Based Nuclear Materials and Fuels; Report Compiled by Singh, R.P.; The Research Foundation of State University of New York: New York, NY, USA, 2008.

21. Ondarcuhu, T.; Joachim, C. Drawing a single nanofibre over hundreds of microns. Europhys. Lett. 1998, 42, 215-220. [CrossRef]

22. Martin, C.R. Membrane-based synthesis of nanomaterials. Chem. Mater. 1996, 8, 1739-1746. [CrossRef]

23. Ma, P.X.; Zhang, R. Synthetic nano-scale fibrous extracellular matrix. J. Biomed. Mat. Res. 1999, 46, 60-72. [CrossRef]

24. Liu, G.; Ding, J.; Qiao, L.; Guo, A.; Dymov, B.P.; Gleeson, J.T.; Hashimoto, T.; Saijo, K. Polystyrene-block-poly (2-cinnamoylethyl methacrylate) nanofibers-Preparation, characterization, and liquid crystalline properties. Chem.-A Eur. J. 1999, 5, 2740-2749. [CrossRef]

25. Bhardwaj, N.; Kundu, S.C. Electrospinning: A fascinating fiber fabrication technique. Biotechnol. Adv. 2010, 28, 325-347. [CrossRef] 
26. Imaizumi, S.; Matsumoto, H.; Konosu, Y.; Tsuboi, K.; Minagawa, M.; Tanioka, A.; Koziol, K.; Windle, A. Top-Down Process Based on Electrospinning, Twisting, and Heating for Producing One-Dimensional Carbon Nanotube Assembly. ACS Appl. Mater. Interfaces 2011, 3, 469-475. [CrossRef]

27. Taylor, G.I. Electrically driven jets. Proc. Soc. R. Lond. A 1969, 313, 453-475.

28. Comyns, A.E.; Gatehouse, B.M.; Wait, E. The chemistry of uranyl acetylacetone complex. J. Chem. Soc. 1958, 4655-4665. [CrossRef]

29. Johnson, D.R. Preparation of $\mathrm{U}_{3} \mathrm{O}_{8}$. U.S. Patent 4,201,738, 6 May 1980.

30. Cotton, S. Lanthanide and Actinide Chemistry; John Wiley \& Sons, Ltd.: Chichester, UK, 2006; Chapter 11.

31. Nolze, G.; Kraus, W. Powder Cell for Windows, Version 2.2; Federal Institute for Materials Research and Testing: Berlin, Germany, 1999.

32. Holland, T.J.B.; Redfern, S.A.T. Unit cell refinement from powder diffraction data: The use of regression diagnostics. Mineral. Mag. 1997, 61, 65-77. [CrossRef]

33. Manara, D.; Boboridis, K.; Morel, S.; De Bruycker, F. The $\mathrm{UC}_{2-x}$-Carbon eutectic: A laser heating study. J. Nucl. Mater. 2015, 466, 393-401. [CrossRef]

34. Richter, H.; Wang, Z.; Ley, L. The one phonon Raman spectrum in microcrystalline silicon. Solid State Commun. 1981, 39, 625-629. [CrossRef]

35. Elorrieta, J.M.; Bonales, L.J.; Rodríguez-Villagra, N.; Baonza, V.G.; Cobos, J. A detailed Raman and X-ray study of $\mathrm{UO}_{2+x}$ oxides and related structure transitions. Phys. Chem. Chem. Phys. 2016, 18, 28209-28216. [CrossRef]

36. Jones, D.W.; McColm, I.J.; Steadman, R.; Yerkess, J. A Neutron-Diffraction Study of the Tetragonal-Monoclinic Crystal Structures of Some Uranium-Thorium Dicarbides. J. Solid State Chem. 1987, 68, 219-226. [CrossRef]

37. Xing, T.; Li, L.H.; Hou, L.; Hu, X.; Zhou, S.; Peter, R.; Petravic, M.; Chen, Y. Disorder in ball-milled graphite revealed by Raman spectroscopy. Carbon 2013, 57, 515-519. [CrossRef]

Publisher's Note: MDPI stays neutral with regard to jurisdictional claims in published maps and institutional affiliations. 